\title{
GRUPUGE PERSPECTIVE: Endoscopic Ultrasound-Guided Biliary Drainage
}

\author{
Nuno Nunes ${ }^{a}$ Margarida Flor de Lima $^{a} \quad$ Ana Caldeira ${ }^{b}$ Sílvia Leite ${ }^{c}$ \\ Susana Marques $^{d}$ Teresa Moreira $^{e}$ Pedro Moutinho-Ribeiro ${ }^{f}$ \\ Miguel Bispo $^{d}$ on behalf of the Portuguese Group for Ultrasound in \\ Gastroenterology (GRUPUGE)
}

${ }^{a}$ Department of Gastroenterology, Hospital do Divino Espírito Santo de Ponta Delgada, Ponta Delgada, Portugal; ' bepartment of Gastroenterology, Hospital Amato Lusitano, Castelo Branco, Portugal; ' ${ }^{\text {CDepartment }}$ of Gastroenterology, Hospital da Senhora da Oliveira, Guimarães, Portugal; d Department of Gastroenterology and Digestive Endoscopy, Champalimaud Foundation, Lisbon, Portugal; ${ }^{\mathrm{D}}$ Department of Gastroenterology, Centro Hospitalar Universitário do Porto - Hospital de Santo António, Porto, Portugal; ${ }^{f}$ Department of Gastroenterology, Centro Hospitalar e Universitário São João, Porto, Portugal

\section{Keywords}

Endoscopic ultrasound · Biliary obstruction .

Biliary drainage $\cdot$ Hepaticogastrostomy .

Choledochoduodenostomy · Rendez-vous technique ·

Gallbladder drainage

\section{Abstract}

Endoscopic ultrasound-guided biliary drainage (EUS-BD) is an alternative to percutaneous and surgical drainage in bile duct obstruction when endoscopic retrograde cholangiopancreatography fails. EUS-BD can be achieved with several techniques, including EUS-guided hepaticogastrostomy (HGS), anterograde transpapillary stent placement, choledochoduodenostomy (CDS), and rendez-vous technique. Late$l y$, with increased experience and development of directed equipment, elevated technical and clinical success as well of lower adverse event rates have been reported. In this article, GRUPUGE presents an updated perspective of the potential role of EUS-guided biliary drainage, addressing the selection criteria and technical issues of different techniques and analyzing recent data on their safety and efficacy.

C 2020 Sociedade Portuguesa de Gastrenterologia Published by S. Karger AG, Basel

karger@karger.com www.karger.com/pjg

Karger

BOPEN ACCESS
(C) 2020 Sociedade Portuguesa de Gastrenterologia Published by S. Karger AG, Basel

This article is licensed under the Creative Commons AttributionNonCommercial-NoDerivatives 4.0 International License (CC BY NC-ND) (http://www.karger.com/Services/OpenAccessLicense). Usage and distribution for commercial purposes as well as any distribution of modified material requires written permission.

\author{
PERSPECTIVA DO GRUPUGE: Drenagem biliar guiada \\ por ecoendoscopia
}

\section{Palavras Chave}

Ecoendoscopia · Obstrução biliar · Drenagem biliar . Hepatogastrostomia · Coledocoduodenostomia · Técnica de rendez-vous · Drenagem da vesícula biliar

\section{Resumo}

A drenagem biliar guiada por ecoendoscopia é uma alternativa à drenagem percutânea ou cirúrgica em casos de obstrução biliar, quando a colangiopancreatografia retrógrada endoscópica (CPRE) falha. Esta poderá ser realizada através de diversas técnicas, incluindo a hepatogastrostomia, colocação de prótese transpapilar por via anterógrada, coledocoduodenostomia e técnica de rendez-vous. Recentemente, têm sido reportadas elevadas taxas de sucesso técnico e clínico, assim como uma menor taxa de efeitos adversos, em relação com o aumento da experiência local e desenvolvimento de dispositivos especializados. No presente artigo, o GRUPUGE apresenta 
uma perspetiva atual do potencial papel da drenagem biliar guiada por ecoendoscopia, focando aspetos relativos à seleção dos doentes, questões técnicas dos vários procedimentos disponíveis e analisando dados emergentes relativos à sua segurança e eficácia.

(c) 2020 Sociedade Portuguesa de Gastrenterologia Publicado por S. Karger AG, Basel

\section{Introduction}

Endoscopic retrograde cholangiopancreatography (ERCP) and placement of a transpapillary stent is considered the first-line procedure for drainage of benign and malignant biliary obstruction [1]. However, ERCP fails in $5-10 \%$ of the patients, even in expert hands, due to anatomic difficulty or inability to cannulate the papilla [2]. Furthermore, several complications following ERCP are described, such as pancreatitis, cholangitis, bleeding, perforation or stent dysfunction requiring reintervention [3].

Endoscopic ultrasound-guided biliary drainage (EUS$\mathrm{BD}$ ) has emerged as an alternative to surgical or percutaneous biliary drainage when ERCP fails $[4,5]$. EUS-BD has elevated technical and clinical success when performed by experts (over 90\%); however, there was concern about the initial reported adverse events rate, apparently related to factors such as the progression in the learning curve, constant equipment exchange, and the lack of dedicated devices [5-7]. Adverse events such as bile leak, peritonitis, cholangitis, self-limited pneumoperitoneum, bleeding and stent migration or dysfunction have been described [7-9]. However, as the local experience increased, latest reports suggest a diminishing rate of related adverse events $(11.9 \%)[6,10]$.

Recently, multicentric prospective randomized studies have compared EUS-BD and ERCP as first-line treatment in cases of malignant biliary obstruction. No significant differences were observed in efficacy and safety [8, 11-13]. Kawakubo et al. [8] suggested a lower risk of developing pancreatitis with EUS-BD [8]. Park et al. [11] reported fewer cases of stent dysfunction due to tumor ingrowth.

EUS-BD can be achieved with several approaches. Intrahepatic techniques include EUS-guided hepaticogastrostomy (HGS) and anterograde transpapillary stent placement. Extrahepatic procedures are choledochoduodenostomy (CDS) and rendez-vous technique. Although CDS and HGS are comparable in technical and clinical success (HGS 93.7\%, CDS 94.1\%), a higher rate of adverse events might be associated with the intra-hepatic access site. According to the pre-existent dilation, CDS may be preferable for a distal common bile duct (CBD) obstruction, whereas HGS for a hilar obstruction [14, 15].

There are reports on several sizes and types of stents used for EUS-BD. Fully covered, self-expandable metalstents (FCSEMS) seem to be superior to plastic and partially covered metal stents in safety and effectiveness [15, 16].

Recently, a lumen-apposing, fully covered nitinolbraided metal stent (LAMS) was developed. The device has bilateral anchor flanges, which allows for better apposition between different surfaces, thereby reducing the probability of leakage and stent migration. When equipped with an enhanced electrocautery delivery system, it permits access and stent introduction in one step, avoiding the need of guidewire manipulation and tract dilation [9, 17-19]. Kunda et al. [9] reported high technical and clinical success rates (98.2 and 96.4\%, respectively) and a 7\% complication rate for CDS using a lumenapposing metal stent. Retrospective analysis of patients submitted to CDS with electrocautery-enhanced LAMS described a technical success of $88.5-93.5 \%$ and a clinical success of $97.7-100 \%$, with a $11.6-13.5 \%$ complications rate. Most of the described complications were solved endoscopically $[18,19]$.

The conducted studies included mostly malignant biliary obstructions. Regarding benign biliary obstructions, rendez-vous technique can be helpful in some cases of inability to cannulate the papilla [20,21]. Moreover, temporary transmural drainage and successive antegrade treatment once the fistula tract has matured has been performed in patients with altered anatomy due to previous surgery $[22,23]$.

In this article, the Portuguese Group for Ultrasound in Gastroenterology (GRUPUGE) presents a perspective of the potential role of EUS-BD, addressing the selection criteria and technical issues of different techniques and analyzing emerging data on their efficacy and safety. A systematic literature search was performed until January 2020, using PubMed, Medline, Scopus and Google, using the keywords "endoscopic ultrasound," "biliary obstruction," "biliary drainage," "hepaticogastrostomy," "choledochoduodenostomy," "rendez-vous technique," and "gallbladder drainage." Prospective/comparative studies and international consensus statements/management guidelines were preferred. The final manuscript was revised and approved by all the members of the Governing Board of the GRUPUGE. 
The procedure should start with the exploration of possible access locations and identification of the drainage site. Puncture of left intrahepatic bile ducts is normally performed from the upper part of the stomach and the CBD from the bulbar portion of the duodenum.

Is it crucial to guarantee the stability of the echoendoscope, avoid large angulations, and assure sufficient dilation of the bile ducts (depending on the type of stent). The absence of blood vessels must be checked, and the minimal distance between the puncture site and the echoendoscope should be used. The puncture may be performed with 19-gauge or 22-gauge needles in order to allow the passage of 0.035 or 0.025 -inch guidewires. It is ideal to obtain a successful access on a first puncture, confirmed by bile aspiration. Contrast injection is usually needed to aid the intervention, except when using LAMS. Looping of the guidewire should be avoided, so the access is not lost. Dilation with cauterization (cystotome) or balloon is currently performed only in the transmural drainage [2426].

The same plane should be maintained in order to assure axial force transmission, confirmed by guidewire monitorization on the ultrasound image or fluoroscopic control [26].

\section{EUS-BD Techniques}

Depending on the clinical case and obstruction location there are several techniques to perform EUS-BD. Intra or extrahepatic access can be obtained and, in both cases, transpapillary or transmural drainage can be performed. Intrahepatic access includes HGS or anterograde stent placement. Extrahepatic access includes CDS and rendez-vous technique.

\section{Rendez-Vous Technique}

Rendez-vous technique is usually performed after failed or impossible cannulation in benign obstructions and in some cases of malignant distal obstruction [24]. This technique implies the EUS-guided puncture of the dilated bile duct followed by the guidewire introduction through the needle, until the ampulla is reached. The echoendocoscope must be in a rectified position with the transductor pointing to the ampulla, contrary to the long position on the bulb. The punction should preferentially be done in the second duodenal portion, near the ampulla $[20,24,25]$.

Endoscopic Ultrasound-Guided Biliary Drainage
Rendez-vous techniques seem to minimize the risk of bile leakage, although limited by the need of an endoscopically accessible ampulla or anastomosis [20]. Another limiting step of this technique is the anterograde manipulation of the guidewire. The guidewire might be misdirected towards the intra-hepatic ducts, which could be avoided by moving to a long scope position, by applying the endoscope tip towards the ampulla or by using a guidewire with an angled tip. On the other hand, if the guidewire does not pass through the ampulla, a papillotome may be passed over the wire to support and steer the wire $[20,24]$.

After transpapillary passage of the guidewire is accomplished, a classic or parallel retrograde biliary access is performed.

\section{Antegrade Transpapillary Stent Placement}

This approach contains the same initial steps as the rendez-vous technique, whereas after insertion of the guidewire, a metallic stent is placed through the ampulla in an antegrade manner $[22,24,25]$. Antegrade stent placement may be used in cases of benign distal bile duct strictures in which retrograde and rendez-vous techniques have failed. However, this technique is technically demanding and does not decrease the risk of pancreatitis [24].

\section{Hepaticogastrostomy}

The HGS implies the placement of a stent between the gastric wall and the intrahepatic bile ducts. HGS is performed in cases of proximal bile duct obstruction with inaccessible papilla or failed cannulation, when the left lobe cannot be drained by ERCP, in cases of surgically altered anatomy or gastric outlet obstruction. Some experts prefer HGS in cases of distal malignant obstruction [24, 26]. HGS should only be performed in cases with significant dilation of the left intrahepatic ducts. Segment III is the preferred puncture site $[25,26]$. Contraindications to HGS include tumor infiltration of the stomach wall (absolute) and massive ascites, coagulopathy or lack of bile ducts dilation (relative) [25].

The transductor should point towards the hepatic hilum and the echoendoscope must be stabilized. It should not rotate so the access is not lost. After puncture, a guidewire is passed into the bile ducts and access can be obtained using cauterization (cystotome 4Fr) or balloon dilation, followed by partially covered hybrid stent deployment over the guidewire [24, 25]. A plastic stent may be used in benign cases to allow sequential access [24].

GE Port J Gastroenterol 2021;28:179-184 181 


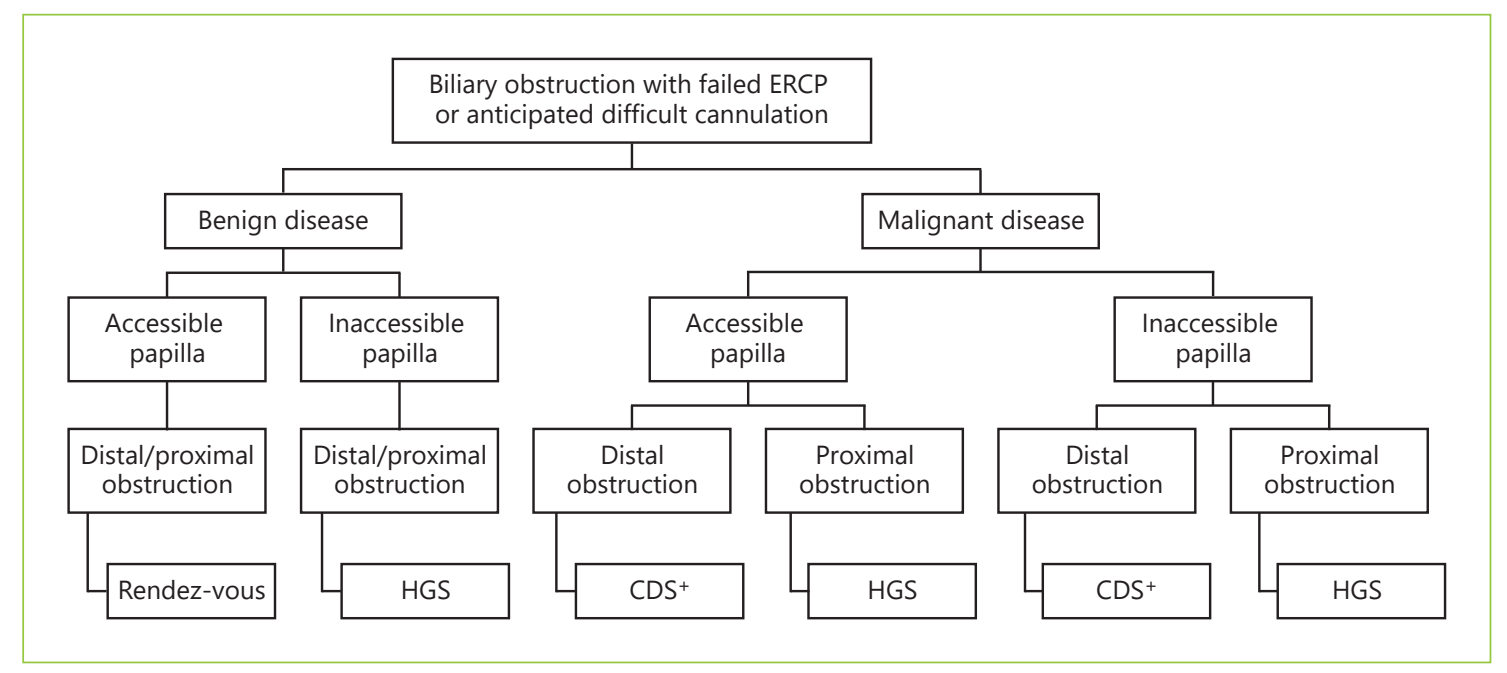

Fig. 1. Algorithm describing the role of EUS-BD in the management of biliary obstructions. Adapted with permission from Hindryckx et al. [24]. CDS: choledochoduodenostomy, HGS, hepaticogastrostomy. ${ }^{+}$In CDS, duodenal patency must be assured. Duodenal stent or an endoscopic gastrojejunostomy placement may be considered.

\section{Choledochoduodenostomy}

This technique provides the placement of a metal stent between the duodenal bulb and the CBD. It is mainly used for malignant CBD obstruction when papillary access is not feasible. [26]. Duodenal patency should be verified before the procedure. A duodenal stent or an endoscopic gastrojejunostomy may be considered before the procedure [24].

CDS can be performed with two approaches. The traditional method achieves biliary drainage using a fully covered metal stent, placed after trans-bulbar puncture of the dilated common bile duct and guidewire insertion into an intrahepatic bile duct. The transductor should be facing the hepatic hilum. The puncture tract is dilated with a cystogastrotome $(6 \mathrm{Fr})$ or a dilation balloon (4 $\mathrm{mm})$ before stent delivery $[9,24,25]$.

The novel alternative uses a lumen-apposing metal stent (LAMS) system. The stent is placed through direct puncture of the dilated duct using an electrocautery-enhanced delivery system and pure cut current, without the need of further dilation. The distal flange is deployed under EUS guidance and the proximal flange under EUS and endoscopic view, confirming correct stent position and adequate biliary drainage [17-19]. Some authors recommend pre-loading a guidewire in the delivery system to proceed in case of misdeployment of the stent [19]. The diameter of the CBD should be superior to $15 \mathrm{~mm}$ in order to provide a safe LAMS delivery [19].
The following algorithm (Fig. 1) suggests a possible role for EUS-BD in the management of biliary obstructions.

\section{Gallbladder EUS-Drainage}

Endoscopic ultrasound-guided gallbladder drainage (EUS-GD) has evolved as an alternative method to percutaneous (PC-GD) or transpapillary gallbladder drainage for patients with acute cholecystitis who are poor surgical candidates [27]. Mohan et al. [28] suggested a better clinical success of EUS-GD comparing to PC-GD or transpapillary gallbladder drainage when performed by skilled endoscopists. Teoh et al. [29] reported a reduced adverse event rate with EUS-GD when compared to PCGD. Technical and clinical success was similar in both techniques. EUS-GD may also be used as palliative treatment in certain cases of malignant biliary obstruction, when other EUS approaches are not feasible, if patency of the cystic duct is assured [30].

The procedure can either be done with placement of a stent (double pigtail, FCSEMS or LAMS) after needle puncture, aspiration with or without cholecystography, guidewire insertion and tract dilation, or directly with deployment of an electrocautery-enhanced LAMS. This technique should be used when the gallbladder is substantially distended and with an echoendoscope in a stabilized position [30]. 
- EUS-BD is the alternative option when ERCP fails.

- In selected cases of malignant obstruction, EUS-BD might eventually be considered a first-line biliary decompression method, although further studies are still needed.

- EUS-BD achieves, in experienced hands, elevated technical and clinical success rates, with an adverse event rate comparable to ERCP and a lower rate of post-procedure pancreatitis.

- In benign biliary obstruction after failed ERCP with an accessible papilla, a rendez-vous approach should be performed.

- In cases of malignant biliary obstruction after failed ERCP, CDS should be performed for distal obstruction and HGS for proximal obstruction.

- EUS-GD might be considered the first choice of drainage for patients with acute cholecystitis who are poor surgical candidates. It may also be used in certain cases of malignant biliary obstruction, when other EUS approaches are not feasible, if patency of the cystic duct is assured.
All authors declare that there are no personal conflicts of interest or financial relationships relevant to this publication.

\section{Funding Sources}

The authors declare that there are none to report.

\section{Author Contributions}

Nuno Nunes and Margarida Flor de Lima: article concept and design, literature review, and draft of the manuscript. Ana Caldeira, Sílvia Leite, Susana Marques, Teresa Moreira, Pedro Moutinho-Ribeiro, and Miguel Bispo: literature review and critical review of the manuscript.

\section{References}

1 Dumonceau JM, Tringali A, Papanikolaou IS, Blero D, Mangiavillano B, Schmidt A, et al. Endoscopic biliary stenting: indications, choice of stents, and results: European Society of Gastrointestinal Endoscopy (ESGE) Clinical Guideline - Updated October 2017. Endoscopy. 2018 Sep;50(9):910-30.

2 Ekkelenkamp VE, de Man RA, Ter Borg F, Borg PC, Bruno MJ, Groenen MJ, et al. Prospective evaluation of ERCP performance: results of a nationwide quality registry. Endoscopy. 2015 Jun;47(6):503-7.

3 Andriulli A, Loperfido S, Napolitano G, Niro G, Valvano MR, Spirito F, et al. Incidence rates of post-ERCP complications: a systematic survey of prospective studies. Am J Gastroenterol. 2007 Aug;102(8):1781-8.

4 Dhir V, Artifon EL, Gupta K, Vila JJ, Maselli $\mathrm{R}$, Frazao M, et al. Multicenter study on endoscopic ultrasound-guided expandable biliary metal stent placement: choice of access route, direction of stent insertion, and drainage route. Dig Endosc. 2014 May;26(3):430-5.

5 Hara K, Yamao K, Hijioka S, Mizuno N, Imaoka $\mathrm{H}$, Tajika M, et al. Prospective clinical study of endoscopic ultrasound-guided choledochoduodenostomy with direct metallic stent placement using a forward-viewing echoendoscope. Endoscopy. 2013;45(5):3926.

6 Khashab MA, Van der Merwe S, Kunda R, El Zein MH, Teoh AY, Marson FP, et al. Prospective international multicenter study on endoscopic ultrasound-guided biliary drainage for patients with malignant distal biliary obstruction after failed endoscopic retrograde cholangiopancreatography. Endosc Int Open. 2016 Apr;4(4):E487-96.

7 Park DH, Jang JW, Lee SS, Seo DW, Lee SK, Kim MH. EUS-guided biliary drainage with transluminal stenting after failed ERCP: predictors of adverse events and long-term results. Gastrointest Endosc. 2011 Dec;74(6): 1276-84.

8 Kawakubo K, Kawakami H, Kuwatani M, Kubota Y, Kawahata S, Kubo K, et al. Endoscopic ultrasound-guided choledochoduodenostomy vs. transpapillary stenting for distal biliary obstruction. Endoscopy. 2016 Feb; 48(2):164-9.

9 Kunda R, Pérez-Miranda M, Will U, Ullrich S, Brenke D, Dollhopf M, et al. EUS-guided choledochoduodenostomy for malignant distal biliary obstruction using a lumen-apposing fully covered metal stent after failed ERCP. Surg Endosc. 2016 Nov;30(11):5002-8.

10 Poincloux L, Rouquette O, Buc E, Privat J, Pezet D, Dapoigny M, et al. Endoscopic ultrasound-guided biliary drainage after failed ERCP: cumulative experience of 101 procedures at a single center. Endoscopy. 2015 Sep; 47(9):794-801.

11 Park JK, Woo YS, Noh DH, Yang JI, Bae SY, Yun HS, et al. Efficacy of EUS-guided and ERCP-guided biliary drainage for malignant biliary obstruction: prospective randomized controlled study. Gastrointest Endosc. 2018 Aug;88(2):277-82.

12 Bang JY, Navaneethan U, Hasan M, Hawes R, Varadarajulu S. Stent placement by EUS or ERCP for primary biliary decompression in pancreatic cancer: a randomized trial (with videos). Gastrointest Endosc. 2018 Jul; 88(1):9-17.

13 Hathorn KE, Bazarbashi AN, Sack JS, McCarty TR, Wang TJ, Chan WW, et al. EUS-guided biliary drainage is equivalent to ERCP for primary treatment of malignant distal biliary obstruction: a systematic review and meta-analysis. Endosc Int Open.2019 Nov;7(11):E143241.

14 Uemura RS, Khan MA, Otoch JP, Kahaleh M, Montero EF, Artifon EL. EUS-guided Choledochoduodenostomy Versus Hepaticogastrostomy: A Systematic Review and Metaanalysis. J Clin Gastroenterol. 2018 Feb;52(2): 123-30.

15 Khashab MA, Messallam AA, Penas I, Nakai Y, Modayil RJ, De la Serna C, et al. International multicenter comparative trial of transluminal EUS-guided biliary drainage via hepatogastrostomy vs. choledochoduodenostomy approaches. Endosc Int Open. $2016 \mathrm{Feb}$; 4(2):E175-81.

16 Park DH, Song TJ, Eum J, Moon SH, Lee SS Seo DW, et al. Clinical outcome of EUS-guided biliary drainage with a transluminal stent for biliary obstruction after a failed ERCP. Gastrointest Endosc. 2010;71(5):AB288. 
17 Brückner S, Arlt A, Hampe J. Endoscopic ultrasound-guided biliary drainage using a lumen-apposing self-expanding metal stent: a case series. Endoscopy. 2015 Sep;47(9):85861.

18 Jacques J, Privat J, Pinard F, Fumex F, Valats JC, Chaoui A, et al. Endoscopic ultrasoundguided choledochoduodenostomy with electrocautery-enhanced lumen-apposing stents: a retrospective analysis. Endoscopy. 2019 Jun; 51(6):540-7.

19 Anderloni A, Fugazza A, Troncone E, Auriemma F, Carrara S, Semeraro R, et al. Singlestage EUS-guided choledochoduodenostomy using a lumen-apposing metal stent for malignant distal biliary obstruction. Gastrointest Endosc. 2019 Jan;89(1):69-76.

20 Park DH, Jeong SU, Lee BU, Lee SS, Seo DW, Lee SK, et al. Prospective evaluation of a treatment algorithm with enhanced guidewire manipulation protocol for EUS-guided biliary drainage after failed ERCP (with video). Gastrointest Endosc. 2013 Jul;78(1):91-101.
21 Dhir V, Bhandari S, Bapat M, Maydeo A. Comparison of EUS-guided rendezvous and precut papillotomy techniques for biliary access (with videos). Gastrointest Endosc. 2012 Feb;75(2):354-9.

22 Weilert F. Prospective evaluation of simplified algorithm for EUS-guided intra-hepatic biliary access and anterograde interventions for failed ERCP. Surg Endosc. 2014 Nov; 28(11):3193-9.

23 Nakai Y, Kogure H, Isayama H, Koike K. Endoscopic Ultrasound-Guided Biliary Drainage for Benign Biliary Diseases. Clin Endosc. 2019 May;52(3):212-9.

24 Hindryckx P, Degroote H, Tate DJ, Deprez $\mathrm{PH}$. Endoscopic ultrasound-guided drainage of the biliary system: Techniques, indications and future perspectives. World J Gastrointest Endosc. 2019 Feb;11(2):103-14.

25 Boulay BR, Lo SK. Endoscopic UltrasoundGuided Biliary Drainage. Gastrointest Endosc Clin N Am. 2018 Apr;28(2):171-85.

26 Mishra A, Tyberg A. Endoscopic ultrasound guided biliary drainage: a comprehensive review. Transl Gastroenterol Hepatol. 2019 Feb; $4: 10$.
27 Mori Y, Itoi T, Baron TH, Takada T, Strasberg SM, Pitt HA, et al. Tokyo Guidelines 2018: management strategies for gallbladder drainage in patients with acute cholecystitis (with videos). J Hepatobiliary Pancreat Sci. 2018 Jan;25(1):87-95.

28 Mohan BP, Khan SR, Trakroo S, Ponnada S, Jayaraj M, Asokkumar R, et al. Endoscopic ultrasound-guided gallbladder drainage, transpapillary drainage, or percutaneous drainage in high risk acute cholecystitis patients: a systematic review and comparative meta-analysis. Endoscopy. 2020 Feb;52(2): 96-106.

29 Teoh AY, Kitano M, Itoi T, Pérez-Miranda M, Ogura T, Chan SM, et al. Endosonographyguided gallbladder drainage versus percutaneous cholecystostomy in very high-risk surgical patients with acute cholecystitis: an international randomised multicentre controlled superiority trial (DRAC 1). Gut. 2020 Jun;69(6):1085-91.

30 Law R, Baron TH. Endoscopic UltrasoundGuided Gallbladder Drainage. Gastrointest Endosc Clin N Am. 2018 Apr;28(2):187-95. 